\title{
Single Incision Laparoscopic Cholecystectomy vs Conventional Cholecystectomy in Developing Country
}

\author{
Thapa PB, 'Maharian DK, 'Singh DR' \\ 'Department of General Surgery, Kathmandu Medical College Teaching Hospital, Kathmandu, Nepal.
}

\section{ABSTRACT}

Introduction: Use of laparoscopic surgery has demanded principles of less trauma of access hence less scar and so probably less complications. Hence conventional laparoscopic surgeries were tried with natural orifice transluminal surgery (NOTES) and then single incision laparoscopic surgery (SILS). With refinement in instruments and surgeons skills SILS have bridged up between conventional and NOTES in order to quench the desire of less or no scar at all.

Methods: Comparative case control study between conventional laparoscopic cholecystectomy and SILS in public teaching hospital.

Results: Total 20 patients underwent SILS cholecystectomy and 20 underwent conventional cholecystectomy and found that no difference between both in terms of post operative pain score, hospital stay and post operative wound infection except significant difference in mean operative time and patient's level of satisfaction was less in patient with SILC if were subjected to pay for instruments in order to maintain cosmesis.

Conclusions: Though SILS have gained rapid acceptance in surgical fraternity, large number of randomized controlled trials are necessary to show its benefit over conventional laparoscopic cholecystectomy.

Keywords: cholecystectomy, conventional, laparoscopy, single incision, surgery

\section{INTRODUCTION}

In era of minimal invasive surgery, with wide spread use of laparoscopic surgery, the tendency of minimizing surgical trauma encourages the use of new approaches of less invasive along with scarless concept like natural orifice trans-luminal surgery (NOTES) and transumbilical single-incision laparoscopic surgery (SILS) are gaining wide acceptance..$^{1-4}$
The aim of the present study was to evaluate the feasibility, safety, cost effectiveness and patient's satisfaction of SILS in developing country Nepal.

\section{METHODS}

A prospective cross sectional study was conducted in department of general surgery, Kathmandu Medical College Teaching Hospital from April - August, 2010. The ethical approval was taken. The counseling of

Correspondence:

Dr. Prabin Bikram Thapa

Department of General Surgery

Kathmandu Medical College Teaching Hospital

Baburam Sadak, Sinamangal, Kathmandu, Nepal.

Email address: prabin_bł@rediff.mail

Phone: 9851002303 
Thapa et al. Single Incision Laparoscopic Cholecystectomy vs Conventional Cholecystectomy in Developing Country

the patients regarding the novel methods was done and informed consent was taken. The patients who were undergoing elective cholecystectomy were grouped into two group - SILS cholecystectomy and Conventional laparoscopic cholecystectomy. There were 20 patient in each group. Those patient who were in the waiting list, developed the feature of acute calculus cholecystitis were excluded from study. The authors have been doing advanced laparoscopic surgeries (Laparoscopic anterior resection, APR, right and left hemicolectomy, splenectomy, nephrectomy) and pioneered SILS cholecystectomy, appendectomy and right hemicolectomy in Nepal after generous donation of SILS PortTM (Covidien, Norwalk, CT, USA) and Roticulated endo grasp (Auto Suture, Norwalk, CT, USA) which was used free of cost after taking approval from concerned authority.

Single Incision Laparoscopic Cholecystectomy (SILC): All patients were admitted one day prior for operation. The operation was performed transumbilically using SILS port TM. Firstly, S-shaped (Ying-Yang) incision made along the curvature of umbilicus and flap was created. The fascia was opened $(2 \mathrm{~cm})$ and the SILS port TM was introduced into the abdomen. After that, two $5 \mathrm{~mm}$ trocars were put through the port and the pneumoperitoneum was induced. A zero degree $10 \mathrm{~mm}$ optic was used in all operations. One straight and one curved grasper (Roticulated endo grasp, Auto Suture, Norwalk, CT, USA) were used initially for two patients, however later conventional laparoscopic instruments were used in all patient. In all cases of cholecystectomy critical view of safety was tried to obtain.

All data were entered prospectively during this period and primary end points were mean operative duration, conversion to conventional laparoscopic cholecystectomy or open cholecystectomy, post operative pain score, mean post operative hospital stay were calculated and secondary end points were patient's satisfaction and perception regarding SILS in terms of cosmesis whether they would recommend any of their family members to undergo same procedure if they had to pay for SILS Port ${ }^{\mathrm{TM}}$.

The data were analyzed with an intention-to-treat principle. The results of SILC and conventional laparoscopic cholecystectomy groups were compared using unpaired $\mathrm{t}$-test and $\chi 2$ test or Fisher's exact test, as appropriate. The $P$ value less than $<0.050$ was considered significant, statistically. The data were analyzed with use of statistical package for social sciences (SPSS) version 16 for windows.

\section{RESULTS}

Altogether 20 patients were operated on by the SILC technique, among which two conversion lone to conventional three port due to bleeding and one conversion to one extra $5 \mathrm{~mm}$ port due to adhesion) and 20 patients were done by conventional three port laparoscopic cholecystectomy among which two conversion to open cholecystectomy due to frozen Calot's triangle. The patients were followed in seven days, 14 days and 30 days post operation and umbilical wound of SILS were recorded photographically.

There was no statistically different between two groups in terms of mean age, gender, conversion rate, mean post operative hospital stay and post operative pain score (Table 1). However, mean operative time period was longer for single incision laparoscopic cholecystectomy (75 mins \pm 5.7 ) than conventional laparoscopic cholecystectomy (39 mins \pm 2.17 ) (P value -0.000). There were no difference in rate of superficial wound infection among both group of patients ( $P$ value $-0.916)$.

When patients were asked about satisfaction level of surgery (according to Likart scale) in terms of cosmesis,

Table 1. Comparison between single incision laparoscopic cholecystectomy (SILC) and conventional laparoscopic surgery.

\begin{tabular}{|c|c|c|c|c|}
\hline SN & Particulars & $\begin{array}{l}\text { SILS cholecystectomy } \\
(N=20)\end{array}$ & $\begin{array}{l}\text { Conventional laparoscopic } \\
\text { cholecystectomy }(\mathrm{N}=20)\end{array}$ & $P$ value \\
\hline 1 & Age mean $( \pm$ S.E) & $45.1 \pm 3.6$ & $41.4 \pm 3.4$ & 0.464 \\
\hline 2 & Sex $(M: F)$ & $5: 15$ & $1: 19$ & 0.77 \\
\hline 3 & Conversion & 2 & 2 & 0.333 \\
\hline 4 & Mean duration of surgery (min.) $\pm \mathrm{S} . \mathrm{E}$ & $75 \pm 5.7$ (30 -120mins) & $39 \pm 2.17$ & 0.000 \\
\hline 5 & $\begin{array}{l}\text { Mean post operative pain score after } 24 \text { hours } \\
\text { (VAS) }\end{array}$ & $4.7 \pm 0.10$ & $5 \pm 0.28$ & 0.324 \\
\hline 6 & Mean duration of hospital stay & $1.0 \pm 0.5$ & $1.3 \pm 0.17$ & 0.187 \\
\hline 7 & Post operative wound infection & 2 & 2 & 0.916 \\
\hline 8 & Patient satisfaction (Likert Scale) & $5.1 \pm 0.22$ & $5.5 \pm 0.228$ & 0.177 \\
\hline 9 & $\begin{array}{l}\text { Recommend to their family members if cost } \\
\text { of respective procedures need to be beared. }\end{array}$ & Yes $-35 \%$; No- $65 \%$ & Yes-67 \%; No-33 \% & \\
\hline
\end{tabular}


Thapa et al. Single Incision Laparoscopic Cholecystectomy vs Conventional Cholecystectomy in Developing Country

there was no significant difference in both groups, $(P$ value - 0.177 ) and $65 \%$ of patient who underwent SILC did not recommend same procedure to their family members if the cost of SILS Port ${ }^{\mathrm{TM}}$ needs to be beared by patient where as $67 \%$ of conventional laparoscopic cholecystectomy agreed for same method if cost is considered.

\section{DISCUSSION}

Laparoscopic surgery has evolved in last two decades and many surgical disciplines have accepted due to novel drive of decreasing morbidity to the patient following surgery with an aim of minimizing the surgical access related trauma as well as cosmetic advantage of having less scar to scarless surgery. ${ }^{5-9}$ Due to later concept of better cosmesis, feasibility of natural orifice transluminal surgery (NOTES) was introduced, however due to expensive instruments and long learning curve it is not easily replicable in developing country due to cost containment. ${ }^{10}$ Hence single incision laparoscopic surgery (SILS) seems to bridge between conventional laparoscopic surgery and NOTES and gaining its wide acceptance due to easy reproducibility of conventional laparoscopic surgical procedure with familiarity of instruments being used and same plane of laparoscopic anatomical vision as the conventional laparoscopic surgery. ${ }^{11-14}$ However, it seems that single incision laparoscopic surgery (SILS) are being confined to developed countries due to cost containment of custom made ports used for single incision surgery. Since then multiple techniques have been described in order to decrease cost like single-incision trans-facial multiport laparoscopic surgery, ${ }^{15}$ use of conventional instruments ${ }^{16}$ or making surgical gloves as port. ${ }^{17}$

In 1997, Navarra et $\mathrm{al}^{18}$ started laparoscopic cholecystectomy with two transumbilical trocars and three transabdominal gall bladder stay sutures. Since only few RCT have been published about its feasibility. ${ }^{19-20}$ However questioned remained unanswered regarding safety to patient, procedural standardization and cost effectiveness. ${ }^{21-3}$ The learning curve time period is difficult and prolonged as compared with conventional laparoscopic cholecystectomy ${ }^{24}$ though few have justified that it have shorter learning curve..$^{25-7}$ The technique can be transferred for surgical population only if it is time tested safe, easily reproducible and makes economical and cultural sense! So, does patient from developing countries like Nepal (where GDP is $\$ 495$ per annum and limited resources for health care service without system of health insurance) benefit from SILS where cost is the major factor for being treated or not and cosmesis is the least priorities subject during treatment due to cultural and social factors?

This study shows the feasibility of SILS in developing countries though small number of cases but its safety could not be established with this study. It becomes expensive if disposable custom made ports and instruments be used for individual patient(total surgical cost :\$750) than conventional laparoscopic cholecystectomy (total surgical cost:\$170), however after use of reusable conventional laparoscopic instruments and single SILS Port ${ }^{\mathrm{TM}}$ for five patients after proper sterilization, cost could be lowered but concerned about surgical safety as it was difficult to achieve the triangle of safety during first three cases and then later could be achieved and ethical issue remains prime concern due to reuse of disposable ports. However, there was no significant difference in satisfaction level (according to Likert scale)among two groups in terms of cosmesis ( $P$ value- 0.177 ), probably this perception could be due to cultural factor as most people still consider cosmesis as least priority during surgery. Similarly, when they were asked about recommendations of similar surgery to their family members if they need to pay for respective surgery, $65 \%$ of SILC group denied for surgery due to cost factor where as $67 \%$ of conventional laparoscopic cholecystectomy patient agreed for it. This finding shows that any new technique introduced to a population should be easily reproducible and moreover should be cost effective in developing countries like Nepal.

\section{CONCLUSIONS}

We recommend the single incision laparoscopic cholecystectomy approach for patients who can afford the cost and are aware of cosmesis, however till the surgeon's hand friendly new instruments are developed in order to follow principle of triangulation in laparoscopic surgery, we are yet skeptical in propagating its wide acceptance in surgical populations for time being as we do not have data of long term follow up in terms of incisional hernia, cost benefit analysis of this procedure. We are trying to evaluate this procedure in a randomized controlled study in terms of safety, patient satisfaction, postoperative pain, cosmesis and associated operative costs in the long run. 
Thapa et al. Single Incision Laparoscopic Cholecystectomy vs Conventional Cholecystectomy in Developing Country

\section{REFERENCES}

1. de la Fuente SG, Demaria EJ, Reynolds JD, Portenier DD, Pryor AD. New developments in surgery: natural orifice transluminal endoscopic surgery (NOTES). Arch Surg. 2007;142:295-97.

2. Marescaux J, Dallemagne B, Perretta S, Wattiez A, Mutter D, Coumaros D. Surgery without scars: report of transluminal cholecystectomy in a human being. Arch Surg. 2007;142:823-6.

3. Zhu JF Scarless endoscopic surgery: NOTES or TUES. Surg Endosc August. 2007;21:1898-9.

4. Zehetner J, Wayand WU. NOTES - a new era? Hepatogastroenterology. 2008;55:8-12.

5. Navarra G, Pozza E, Occhionorelli S, Carcoforo P, Donini I. One-wound laparoscopic cholecystectomy. Br J Surg. 1997;84:695.

6. Piskun G, Rajpal S. Transumbilical laparoscopic cholecystectomy utilizes no incisions outside the umbilicus. J Laparoendosc Adv Surg Tech A. 1999;9:361-4.

7. Tacchino R, Greco F, Matera D. Single-incision laparoscopic cholecystectomy: surgery without a visible scar. Surg Endosc. 2009;23:896-9.

8. Cuesta MA, Berends F, Veenhof AA. The "invisible cholecystectomy". A transumbilical laparoscopic operation without a scar. Surg Endosc. 2008;22:1211-3.

9. Rao PP, Bhagwat SM, Rane A, Rao PP. The feasibility of single port laparoscopic cholecystectomy: a pilot study of 20 cases. HPB (Oxford). 2008;10:336-40.

10. Sodergren MH, Clark J, Athanasiou T, Teare J, Yang GZ, Darzi .A Natural orifice transluminal endoscopic surgery: critical appraisal of applications in clinical practice. Surg Endosc. 2009;23:680-7.

11. Hirano Y, Watanabe T, Uchida T, Yoshida S, Tawaraya K, Kato $\mathrm{H}$, et al. Single-incision laparoscopic cholecystectomy: Single institution experience and literature review. World J Gastroenterol. 2010;16(2):270-4.

12. Hong TH, You YK, Lee KH. Transumbilical single-port laparoscopic cholecystectomy: scarless cholecystectomy. Surg Endosc. 2009 Jun;23(6):1393-7.

13. Tacchino R, Greco F, Matera D. Single-incision laparoscopic cholecystectomy: surgery without a visible scar. Surg Endosc. 2009 Apr; 23(4):896-9.

14. Rivas H, Varela E, Scott D. Single-incision laparoscopic cholecystectomy: initial evaluation of a large series of patients. Surg Endosc 2010;24:1403-12.
15. Gumbs AA, Milone L, Sinha P, Bessler M. Totally transumbilical laparoscopic cholecystectomy. J Gastrointest Surg. 2009 Mar;13(3):533-4.

16. Philipp SR, Miedema BW, Thaler K. Single-incision laparoscopic cholecystectomy using conventional instruments: early experience in comparison with the gold standard. J Am Coll Surg. 2009 Nov;209(5):632-7.

17. Kuon Lee S, You YK, Park JH, KimHJ, Lee KK, Kim DG. Single-port transumbilical laparoscopic cholecystectomy: a preliminary study in 37 patients with gallbladder disease. J Laparoendosc Adv Surg Tech A. 2009;19:495-9.

18. Navarra G, Pozza E, Occhionorelli $S$ et al. One wound laparoscopic cholecystectomy. Br J Surg. 1997;84:695.

19. Navarra G, La Malfa G, Bartolotta G, Currò G. The invisible cholecystectomy: a different way. Surg Endosc. 2008;22:2103.

20. Cugura JF, Janković J, Kulis T, Kirac I, Beslin MB. Single incision laparoscopic surgery (SILS) cholecystectomy: where are we? Acta Clin Croat. 2008;47:245-8.

21. Rao PP, Bhagwat SM, Rane A, et al. The feasibility of single port laparoscopic cholecystectomy: A pilot study of 20 cases. HPB (Oxford). 2008;10:336-40.

22. Bucher P, Pugin F, Buchs N, Ostermann S, Charara F, Morel P. Single port access laparoscopic cholecystectomy (with video). World J Surg. 2009;33:1015-9.

23. Lee PC, Lo C, Lai PS, Chang JJ, Huang SJ, Lin MT, et al. Randomized clinical trial of single-incision laparoscopic cholecystectomy versus minilaparoscopic cholecystectomy. Br J Surg. 2010 Jul;97(7):1007-12.

24. Antoniou SA, Pointner R, Granderath FA. Single-incision laparoscopic cholecystectomy: a systematic review. Surg Endosc. 2010 Jul 7. [Epub ahead of print]

25. Chow A, Purkayastha S, Paraskeva P. Appendicectomy and cholecystectomy using single-incision laparoscopic surgery (SILS): the first UK experience. Surg Innov. 2009;16(3):211-7.

26. Tsimoyiannis EC, Tsimogiannis KE, Pappas-Gogos G, Farantos C, Benetatos N, Mavridou P, et al. Different pain scores in single transumbilical incision laparoscopic cholecystectomy versus classic laparoscopic cholecystectomy: a randomized controlled trial. Surg Endosc. 2010;24(8):1842-8.

27. Ersin S, Firat O, Sozbilen M. Single-incision laparoscopic cholecystectomy: is it more than a challenge? Surg Endosc. 2010;24:68-71. 